\title{
Understanding Factors Related with Cheating in Sport: What We Know and What is Worth Future Consideration
}

\author{
Beatričè Sipavičiūtė, Saulius Šukys \\ Lithuanian Sports University, Kaunas, Lithuania
}

\begin{abstract}
Background. Over the past decade, there has been an increase in scholars' attention to moral behaviour in sport. Recently more studies have been dealing with cheating with a special focus on doping. The aim of this study was to provide an overview of research focusing on cheating in sport. Specifically, the purpose was to critically analyse research on personal and social factors which have been associated with an intension to cheat and cheating behaviour.

Methods. Scientific research analysis on social environment factors related with cheating was carried out focusing on personal and social environmental factors related with athletes' attitudes towards, intention and cheating behaviours.

Results. Moral identity is an important factor for cheating in sport and intention to use doping. A negative relation was found between moral values of athletes and doping likelihood. Also, when athletes perceive their goal only as winning the game (goal-oriented rather than task-oriented), they are more likely to cheat. Furthermore, recent studies have found the relationship between the Dark Triad (Machiavellianism, narcissism, and psychopathy) and the use of doping in sport. Moreover, perfectionism involves positive attitudes towards doping and actual use of doping. Also, there is evidence that moral values relate with athletes' cheating and gamesmanship. Some social environment factors related with motivational climate created by the coach and parents. Coaches and parents created an egooriented climate associated with young athletes' positive attitudes towards cheating.

Conclusion. Athlete's intention to cheat or actual behaviour is determined by both athlete's personality and social environment context. The article also provides considerations of directions for future research with special attention to cultural differences.
\end{abstract}

Keywords: cheating, doping, moral identity, motivational climate, personality traits.

\section{INTRODUCTION}

I

1994, a day before the U.S. Figure Skating Championship, Nancy Kerrigan was attacked by a man who hit her right leg. It was alleged that the attacker was sent by her skating opponent Tonya Harding. Tonya Harding was found guilty and banned from the U.S. Figure Skating Association for good. Obviously, losing a career is the biggest punishment for a promising athlete. So why do athletes risk their careers by cheating?

Cheating is not some unusual phenomenon. As Russell states, "People cheat on their taxes, on their spouses, on their friends, on their clients, on tests, on resumes, on expense claims, on safety reports, and of course people cheat in sport. There is hardly an area of life where cheating cannot be identified often as a serious problem" (2014, p. 304). So, cheating in sport occurs and can create various ethical dilemmas. Therefore, there is no coincidence that in the last decade there was an increased interest of scholars in moral behaviour of athletes (Kavussanu, 2019). Special attention is paid to prosocial and antisocial behaviours. Scholars associate antisocial behaviour of athletes with intimidation of the opponent, intention of frightening the opponent, the use of physical aggression and cheating (Sage, Kavussanu, \& Duda, 2006). There are science-based research tools which allow to examine social and antisocial 
behaviours in sport (Kavussanu \& Boardley, 2009), and much is known about moral behaviour factors in sport already (Kavussanu, 2019). On the other hand, in the context of antisocial behavioural research, only in recent years particular attention has been paid to cheating in sport (Vorstenbosch, 2010), although cheating itself is quite an old phenomenon (De Rose, 1996).

As research analysis on cheating in sport during the last decade has increased, it is worth performing more comprehensive analysis of such studies. Given the various forms of cheating and studies more focusing on some of them, this review is not an exhaustive analysis. Rather, its purpose is to provide an overview of research focusing on cheating in sport. Specifically, the purpose is to critically analyse research on personal and social factors which have been associated with the intension to cheat and cheating behaviour. The article starts by throwing some light on the definition of cheating in sport. It continues by reviewing personal factors related with cheating and focuses on moral identity, personal goals, perfectionism, personality traits and values. Further, we analyse scientific research on social environment factors related with cheating and focus on coach created motivational climate, the coach's attitudes towards cheating and parents' influence on young athletes' cheating behaviour.

\section{RESULTS}

\section{The concept of cheating in sport}

One of the key features of cheating is to benefit yourself or your team, get competitive advantage and maintain continuity of athletic game (Loland, 2002; Strand, Brotherson, \& Tracy, 2018). Cheating in sport can be related to deception, lying, violation of rules, imitating and impersonating (Vorstenbosch, 2010). An athlete may lie, cheat, use doping or violate the rules of the game (Vorstenbosch, 2010) to achieve their goals and gain a competitive advantage. However, professional fouls such as in basketball are not considered cheating. Such a foul is called gamesmanship (Potgieter, 2013). Gamesmanship is an attempt to win a game without obvious cheating, such as wasting match time, pretending to be injured or trying to irritate the opponent (Ponseti, Cantallops, \& MuntanerMas, 2016). Furthermore, athletes can manipulate the rules, even though they actually do not violate them, or use psychological manipulations against the opponent to gain a competitive advantage in the game (Strand et al., 2018).
It is known that cheating in sport can be divided into deviant and institutionalized (Eitzen, 1979). Institutionalized cheating is a wrongful behaviour of an athlete, such as wasting time, which is recognized as part of a game (Potgieter, 2013). Deception, violence and aggression can be accepted, too. Meanwhile, a deviant cheating, such as accepting bribes or the use of doping, is indefensible and punished (Potgieter, 2013).

\section{Personal factors as predictors of cheating} in sport

2.1. Moral identity as negative predictor of cheating in sport. Analysis of the scientific literature has revealed that cheating depends on both personal and social factors. When considering personal factors, one of the most important to mention is the moral factor, specifically moral identity. Psychological construct of moral identity, as a self-regulatory mechanism (Aquino \& Reed, 2002) is based on Bandura's (1991) social cognitive model of moral behaviour. Aquino and Reed (2002) defined moral identity as "a self-conception organized around a set of moral traits" (Aquino $\&$ Reed, 2002, p. 1424). Authors also suggest that people vary in the degree to which they consider being a good or moral person, a central part of their self-concept. Moral identity is a source of motivation to behave morally. In the context of sport, it was found that athletes who have low morale tend to be more positive about cheating (Gucciardi, Jalleh, \& Donovan, 2011; Jalleh, Donovan, \& Jobling, 2014; Nicholls et al., 2015). Some recent studies confirmed that moral identity negatively correlated with doping likelihood (Ring, Kavussanu, \& Hurst, 2018). Another study conducted by Kavussanu and Ring (2017) also confirmed that athletes who felt that being a moral person was central to their selfconcept were less likely to use banned substances to enhance their performance. This study also found that the relationship between moral identity and doping likelihood was also mediated by anticipated guilt. Based on these results the authors argue that athletes with a strong moral identity may be deterred from using banned substances because they would expect to experience intense guilt for acting in this manner. Similarly, other studies found that personal ability reflected in the temptation to use doping was also an important factor (Corrion, Scoffier-Meriaux, \& d'Arripe-Longueville, 2017).

2.2. Achievement orientation as a negative and a positive predictor of cheating in sport. As sport is an achievement context, it requires 
some competency. According to Achievement Goal Theory (Nicholls, 1989), the pursuit of achievement is related to the display of competence and to personal perceptions of success. There are two major ways that success is defined and competence is evaluated, and these are embedded within two achievement goals: task orientation and ego orientation. Task-oriented individuals tend to evaluate competence using self-referenced criteria and feel successful when they master a task, work hard to accomplish a personal goal, or show personal improvement. In contrast, ego-orientated individuals tend to use other referenced criteria to evaluate their competence and define success as superiority over others (Chatzisarantis et al., 2016; Kavussanu \& Ntoumanis, 2003).

Studies have shown that if athletes perceive their goal as winning the game (goal-oriented rather than task-oriented), they are more likely to cheat (Ntoumanis, Ng, Barkoukis, \& Backhouse, 2014). Recent research shows that athletes who have a tolerant attitude towards cheating are characterized as having a higher ego and a lower task orientation (Ring \& Kavussanu, 2018), suggesting that egorelated purpose and desire to "win at all costs" lead athletes to cheating.

Some studies examined association between achievement goals and self-reported performanceenhancing drug use (Barkoukis, Lazuras, Tsorbatzoudis, \& Rodafinos, 2011). It was found that athletes with a stronger mastery achievement goal reported lower past doping use and lower intention for future use. Goal orientation is related with athletes' attitudes towards cheating in sport. As it was reported in a study by Allen, Taylor, Dimeo, Dixon and Robinson (2015), ego orientation was associated with greater endorsement of doping whereas task orientation was associated with more favourable attitudes towards anti-doping.

2.3. Athlete's personality traits and cheating in sport. Factors such as personality traits also need to be addressed. Cheating, such as intentional fouls, doping, injury to opponents and overly aggressive behavior in sport in order to win a match at any cost, is possibly related to the Dark Triad (Furnham, Richards, \& Paulhus, 2013). The term "Dark Triad" was introduced by Paulhus and Williams (2002), and contains three related, but distinct personality traits: Machiavellianism, narcissism, and psychopathy (Azizli et al., 2016). Machiavellianism is characterized by the exploitation of other people and manipulation (Hern et al., 2006), psychopathy is characterized by impulsiveness, ruthlessness and selfishness (Barlett, 2016). Narcissistic people have an over-inflated view of themselves, are vain, and have a strong sense of self-entitlement (Raskin \& Hall, 1979).

However, up to now, only a small number of international studies have been conducted on the role of the Dark Triad in the competitive sport. Research reveals relation to the aforementioned personality traits and attitudes towards cheating (Lyons \& Brockman, 2017; Nicholls, Madigan, Backhouse, \& Levy, 2017). Nicholls et al. (2017) show that in general the Dark Triad personality traits have a significant relation to the tendency to use doping but when assessing these personality traits separately, psychopathy and Machiavellianism show a significantly higher relation to positive attitudes toward doping while narcissism does not show such a strong relation. Therefore, narcissism may be not as important to doping compared to Machiavellianism and psychopathy. Recently Nicholls et al. (2019) re-examined the relationship between the Dark Triad and attitudes towards doping. It was found that all the Dark Triad dimensions were positively correlated with attitudes towards doping and cheating behaviours. Moreover, when controlling for the overlap between traits, the study results have shown that only psychopathy emerged as a positive predictor of attitudes towards doping, and only narcissism emerged as a positive predictor of cheating behaviours.

2.4. Perfectionism and cheating in sport. As sport is associated with the pursuit of certain and often very explicit goals, researchers note perfectionism as one of the factors of cheating. In sports, perfectionism is defined by striving for flawlessness and setting excessively highperformance standards (Flett \& Hewitt, 2002). Perfectionism consists of several factors such as parental and coach pressure and perfectionist's aspirations and concerns (Madigan, Stoeber, \& Passfield, 2016). Perfectionist's aspirations show athlete's desire to be perfect, which creates extremely high personal standards for athletes. Perfectionist's concerns show athlete's concerns about potential mistakes in the match and wish to meet the expectations. Due to high pressure from parents and coach to be perfect, both the athlete's desire to increase athletic potential and the athlete's desire to win the match are associated with perfectionism (Stoeber, Stoll, Pescheck, \& Otto, 2008). According to Flett and Hewitt (2014), 
perfectionism can be an important factor in the tendency of athletes to use doping.

Numerous of studies suggest that perfectionism could be linked with athletes' more positive attitudes towards doping (Bahrami, Yousefi, Kaviani, \& Ariapooran, 2014; Madigan, Stoeber, \& Passfield, 2016; Zucchetti, Candela, \& Villosio, 2015). Thus, unrealistic and unreasonably high personal standards set by athletes and excessive concern for personal mistakes are associated with positive attitudes towards doping in sport (SasNowosielski \& Budzisz, 2017). Also, it was found that perfectionism was related with personal preferences for doping (Flett \& Hewitt, 2014). Gardener and Steinberg (2005) argue that athletes tend to use doping because they value the positive benefits of doping without neglecting the negative consequences, i.e., the potential for harm to their health. Discussing perfectionism and the use of doping, Petróczi (2013) claims that it is important to distinguish between internal and external rewards in the doping mind-set as doping may be used for different goals: to maximise or minimize the chance to win. Interestingly, it has been reported that perfectionism in sport is related to both of these goals (Stoeber et al., 2008).

2.5. Personal values and cheating in sport. Analysing personal factors, the importance of values is worth noting. In sports context, studies by Lee et al. (2008) established that values served as a guide for decision-making and behaviours in sport. On the other hand, research focusing on the relationship between athletes' values and cheating in sport is still scarce. However, some recent studies brought some new insight on this relationship. A study by Ring, Kavussanu and Hurst (2018) found that moral values were negatively associated with athletes' doping likelihood. Moreover, moral values moderated the effects of moral disengagement on doping likelihood. Another study with adolescent tennis players also found that moral values were negatively and directly associated with tennis players' cheating and gamesmanship attitudes (Luicidi et al., 2017). This study also found that moral values directly and positively correlated with athletes' prosocial attitudes. Moreover, this study also yields effect of moral values on cheating behaviour through the antisocial attitudes.

\section{Social environmental factors as predictors of cheating in sport}

Discussion of social environmental factors predicting athletes' attitudes toward some behaviours, intention or actual behaviours shows that coaches and teammates are the most significant individuals within the athletes' social environment (Kavussanu, 2019). Parents also play an important role in shaping athletes' behaviours (Kavussnau, 2019).

Motivational climate in the team created by the coach can be an important contributor for athlete's intentions and behaviour. Based on the Achievement Goal Theory (Nicholls, 1989), climate can be taskinvolving and ego-involving. Accordingly, a taskinvolving climate is defined by situations where the coach focuses on skill improvement, individual progress, and encourages cooperation with others, and in which every individual has an important role in the team. And vice versa, an ego-involving climate involves the use of normative-based evaluation, emphasis on competition, and social comparison between participants. Several studies have shown that the non-ego-oriented climate created by the coach is associated with athletes' prosocial behaviours (Duda \& Balaguer, 2007). On the other hand, a high ego motivational climate is significantly associated with greater acceptance of physical intimidation and lower team morale (Miller, Roberts, \& Ommundsen, 2005), therefore an ego-oriented athlete has a higher risk to behave antisocially (Duda \& Balaguer, 2007).

Therefore, examining the association between motivational climate and antisocial behaviour, it is clear that result-oriented climate created by coaches is associated with cheating in sport (Palou et al., 2013). Similarly, studies on athletes' attitudes towards doping also reported that task orientation (namely master climate) led to a task goal orientation (Kavussanu, 2007). As it was previously mentioned, athlete's task orientation can be related to negative attitude toward cheating in sport. Moreover, studies have shown that coachcreated mastery climate was negatively related with athlete's attitudes towards doping (Allen et al., 2015).

Influence of team leaders should be also noted because the role of the leader can empower cheating decisions (Cope, Eys, Beauchamp, Schinke, \& Bosselut, 2011). Moreover, subjective and descriptive norms also can influence social pressure to perform some behaviour. In other words, subjective norms are related with the extent to which important others in their environment would approve the use of cheating to enhance their performance, while descriptive norms are related 
with the extent of possibilities to cheat within teammates. Studies with adolescents showed that subjective and descriptive norms positively predicted doping intention (Lazuras et al., 2017, Lazuras, Barkoukis, \& Tsorbatzoudis, 2015).

Another social environmental factor is the interpersonal coaching style, which can be controlling and autonomy-supportive (Kavussanu, 2019). Controlling style is related with coaching behaviours in an authoritarian way, while autonomy-supportive style is related with opportunities to show initiative and independent work, non-controlling competence feedback and acknowledgement of their feelings combined with a lack of guilt inducing criticism and overt control. A recent study conducted with Greek athletes showed that controlling coaching environments that frustrate athletes' psychological needs have the potential to foster low moral functioning and positive intentions toward doping, which in turn can result in sustained doping behaviour (Ntoumanis, Barkoukis, Gucciardi, \& Chan, 2017). This study also found that favourable attitudes of athletes toward cheating were a positive predictor of doping intentions. Also, the coach's attitude toward doping is an important factor that influences the adolescent athlete's decision to use doping (Erickson, McKenna, \& Backhouse, 2015).

The role of parents in sport is also important in many aspects in general (Harwood \& Knight, 2015), and among these studies some emphasized the influence on athlete's intention to cheat and cheating in sport. Interviews with currently or previously working with adolescent athletes' coaches (Nicholls et al., 2015) showed that both parents' and coaches' attitudes towards doping influenced adolescent athletes' attitudes towards doping, both negative or positive. Also, adult athletes emphasized not only the role of coaches, but also the role of parents when talking about the causes of adolescent athletes to cheat (Šukys, Karanauskienė, \& Šmigelskaite, 2019). Moreover, sometimes parents want their children to win more than children themselves. Accordingly, adult athletes noted that when children engaged in sports, they were generally less likely to cheat, but sometimes adults encouraged them to do that.

Coach-created motivational climate has already been mentioned. But parents also have an impact on the motivational climate in sport, and the role of both parents can differ. Palou et al. (2013) investigated acceptance of gamesmanship and cheating in young competitive athletes in relation to the motivational climate generated by parents and coaches. Comparing the influence of father and mother in the formation of motivational climate for the child, it was found that the father, unlike the mother, created a result-oriented motivational climate. Meanwhile, mothers were perceived as promoting learning mastery-oriented behaviours.

\section{DISCUSSION}

Analysis of the scientific literature has revealed that in recent years more and more studies have been carried out on cheating, and in particular the intention to use doping. Though there is a lot of scientific literature that analyse the concept of cheating in sport, there is also a growing number of empirical studies that try to explain factors related to athletes' attitudes toward cheating, intention to cheat and cases of cheating. Although different studies address different factors and sometimes even a combination of these factors, in this article we tried to summarize personal and social environment factors related with cheating in sport separately.

When looking deeper into personal factors, research revealed the role of moral identity in athletes' attitudes toward cheating in sport and intentions to use doping. It is important to note that these studies also revealed the importance of feeling guilty. It is evident from the studies reviewed in this article that goal orientation is related with cheating. When athletes perceive their goal as winning the game (goal-oriented rather than task-oriented), they are more likely to cheat, more tolerant towards cheating, and have less favourable attitudes towards anti-doping.

Research started investigating the association between personality traits and cheating in sport. More specifically, recent studies have found the relationship between the Dark Triad, which contains related but distinct traits: Machiavellianism, narcissism, and psychopathy. Although they all are related to athletes' attitudes toward cheating, the relationship between each trait is different. To be more specific, psychopathy was found as a positive predictor of attitudes towards doping, and only narcissism emerged as a positive predictor of cheating behaviours.

Competition and pursuit of goals are integral elements in sport that are perceived by athletes. At the same time, striving for the highest achievements 
requires a perfect performance of athletes. Perfectionism, especially when unrealistic goals are set, involves not only more positive attitudes towards doping, but also more positive references to doping and also doping use. At the same time, it is important to note that adolescent athletes are often encouraged not only by their coaches but also by their parents. Therefore, the relation of perfectionism with cheating is a more complex phenomenon as it can be seen from this article.

It should be noted that values of athletes have generally been less focused on analysing the athletes' behaviours. For example, in scientific research conducted by Kavussanu (2019) on variables that have been consistently associated with transgressive behaviour in sport in the last ten years, the values of athletes were mentioned when discussing about coaches' impact on athletes. Though researchers had investigated the relationship between values and cheating, a negative relation was found between moral values of athletes and doping likelihood. However, more research should be done on personal values, specifically on values related to cheating in sport.

Athletes are greatly influenced by others, especially the coach. Analysis of the research showed some key issues with the coach. The motivational climate created by the coach influences athletes' attitudes towards cheating, especially when the coach creates an ego-oriented climate related to positive attitudes towards cheating.

The coaching style determines athletes' intention to cheat and use doping. Such athletes' intentions may be influenced by an authoritarian style of coaching which can cause fear and anxiety for athletes. The coach can influence the overall team atmosphere too. If there is a positive attitude towards cheating among athletes in the team, it may also encourage individual athletes to take a more positive attitude towards cheating.

Although parents usually wish the good for their children, research shows that parents' role is not always positive in relation to the attitude towards cheating among young athletes. Parents help to create motivational climate in sport, and as a coach, parents can create task or egooriented climate. In addition, parental pressure on accomplishments and exaggerated expectations of their children in sport can encourage children to pursue perfectionism, which can lead to the pursuit of goal by unethical means. Since the role of father and mother in creating a motivating climate in sport is not the same, future research should pay more attention to this when evaluating parenting variables.

In conclusion, the review did not analyse the relation of role of moral disengagement and cheating in sport. In future research, the role of this very important variable must also be considered as it was documented that moral disengagement is a popular mediator between personal and social variables and athletes' behaviours in sport (Kavussanu, 2019). Another important issue for future studies is related with the use of sport supplements and athletes' intention to cheat. Support for such research was provided by a recent study which suggested that athletes who believed that sport supplements were effective, were more likely to use doping (Hurst, Kavussanu, Boardley, \& Ring, 2019).

Previous studies have focused more on doping. This can be partially understood because doping cases are more prominent when athletes are caught using sports supplements. Such cases affect not only athletes, but also certain responsible organizations. In addition, doping is not only against fair play, but also can have negative effects on athletes' health. On the other hand, doping is just one form of cheating. This does not mean that further research should focus less on doping issues. However, we also need more research on other forms of cheating, especially in children and youth sport.

We hope that this overview could be an important impulse for new studies in Lithuania. Currently, there is lack of such research and only several surveys were conducted related to coaches' (Šukys \& Nickus, 2010) and athletes' (Šukys, 2013) attitudes towards cheating in sport, and qualitative study on how adult athletes perceived cheating in sport (Šukys, Karanauskienè, \& Smigelskaite, 2019). In general, research has shown that attitudes towards cheating are not the same when comparing populations in different countries (Magnus, Polterovich, Danilov, \& Savvateev, 2002). Therefore, some data may not necessarily be directly applicable to other cultures. In sports context, Luicidi et al. (2017) pointed out that certain moral codes and athlete training climate may have common and similar, but also distinct features. Similarly, validity of revision research instruments in different cultures is also an important issue.

\section{CONCLUSIONS}

Cheating in sport can be related to lying, deception and violation of rules. An athlete may cheat and use doping to achieve his goal and gain 
competitive advantage. Cheating is opposite to moral behaviour in sport as it is everywhere else. Similarly, as other forms of behaviour which contradict with morality, athlete's intention to cheat or actual behaviour is determined by both athlete's personality and social context. Athlete's moral identity, perception of success in sport, pursuit of perfectionism, personality traits and values influence athletes' intentions to use doping or actual behaviours. Also, the motivational climate created by the coach that emphasizes winning as perception of success, restricts athlete's autonomy and tolerates team-related cheating norms affects athlete's own attitudes toward such behaviour or intention to cheat.

\section{REFERENCES}

Allen, J., Taylor, J., Dimeo, P., Dixon, S., \& Robinson, L. (2015). Predicting elite Scottish athletes' attitudes towards doping: Examining the contribution of achievement goals and motivational climate. Journal of Sports Sciences, 33(9), 899-906. doi: 10.1080/02640414.2014.976588.

Aquino, K., \& Reed, A. (2002). The self-importance moral identity. Journal of Personality and Social Psychology, 83(6), 1423-1440. doi: 10.1037/00223514.83.6.1423.

Azizli, N., Atkinson, B. E., Baughman, H. M., Chin, K., Vernon, P. A., Harris, E., \& Veselka, L. (2016). Lies and crimes: Dark Triad, misconduct, and high-stakes deception. Personality and Individual Differences, 89, 34-39. doi: /10.1016/j.paid2015.09.034.

Bahrami, S., Yousefi, B., Kaviani, E., \& Ariapooran, S. (2014). The prevalence of energetic drugs use and the role of perfectionism, sensation seeking and physical selfconcept in discriminating bodybuilders with positive and negative attitude toward doping. International Journal of Sports Studies, 4(1), 174-180.

Bandura, A. (1991). Social cognitive theory of moral thought and action. In W. M. Kurtines, J. L. Gewirtz (Eds.), Handbook of Moral Behavior and Development: Theory, Research, and Applications (Vol. 1, pp. 45-103). Hillsdale, NJ: Lawrence Erlbaum Associates.

Barkoukis, V., Lazuras, L., Tsorbatzoudis, H., \& Rodafinos, A. (2011). Motivational and sportspersonship profiles of elite athletes in relation to doping behavior. Psychology of Sport and Exercise, 12(3), 205-212. doi: /10.1016/j.psychsport.2010.10.003.

Barlett, C. P. (2016). Exploring the correlations between emerging adulthood, Dark Triad traits, and aggressive behavior. Personality and Individual Differences, 101, 293-298. doi: 10.1016/j.paid.2016.05.061.

Chatzisarantis, N. L. D., Ada, E. N., Bing, Q., Papaioannou, A. G., Prpa, N., \& Hagger, M. S. (2016). Clarifying the link between mastery goals and social comparisons in classroom settings. Contemporary Educational Psychology, 46, 61-72. doi: 10.1016/j. cedpsych.2016.04.009.

Cope, C. J., Eys, M. A., Beauchamp, M. R., Schinke, R. J., \& Bosselut, G. (2011) Informal roles on sport teams. International Journal of Sport and Exercise Psychology, 9(1), 19-30. doi: 10.1080/1612197X.2011.563124.

Corrion, K., Scoffier-Meriaux, S., \& d'ArripeLongueville, F. (2017). Self-regulatory mechanisms of doping intentions in elite athletes: The role of self-determined motivation in sport. Journal of Sports Medicine \& Doping Studies, 7(4), 197. doi: 10.4172/2161-0673.1000197.

De Rose, J. C., De Souza, D. G., \& Hanna, E. S. (1996). Teaching reading and spelling: Exclusion and stimulus equivalence. Journal of Applied Behavior Analysis, 29(4), 451-469. doi: 10.1901/jaba.1996.29-451.

Duda, J. L., \& Balaguer, I. (2007). Coach-created motivational climate. In S. Jowett \& D. Lavallee (Eds.), Social psychology in sport (pp. 117-130). Leeds, UK: Human Kinetics.

Eitzen, D. S. (1979). Sport in contemporary society: An anthology. New York, NY: St. Martin's Press.

Erickson, K., McKenna, J., \& Backhouse, S. H. (2015). A qualitative analysis of the factors that protect athletes against doping in sport. Psychology of Sport and Exercise, 16, 149-155. doi: 10.1016/j.psychsport.2014.03.007.

Flett, G. L., \& Hewitt, P. L. (2002). Perfectionism and maladjustment: An overview of theoretical, definitional, and treatment issues. In G. L. Flett \& P. L. Hewitt (Eds.), Perfectionism: Theory, research, and treatment (pp. 5-31). American Psychological Association.

Flett, G. L., \& Hewitt, P. L. (2014). "The perils of perfectionism in sports" revisited: Toward a broader understanding of the pressure to be perfect and its impact on athletes and dancers. International Journal of Sport Psychology, 45(4), 395-407. doi: 10.7352/ IJSP2014.45.395.

Furnham, A., Richards, S. C., \& Paulhus, D. L. (2013). The Dark Triad of personality: A 10-year review. Social and Personality Psychology Compass, 7(3), 199-216. doi: $10.1111 / \mathrm{spc} 3.12018$.

Gardener, M., \& Steinberg, L. (2005). Peer influence on risk taking, risk preference, and risky decision making in adolescence and adulthood: An experimental study. Developmental Psychology, 41(4), 625-635. doi: 10.1037/0012-1649.41.4.625

Gucciardi, D., Jalleh, G., \& Donovan, R. J. (2011). An examination of the sport drug control model with elite Australian athletes. Journal of Science \& Medicine in Sport, 14(6), 469-476. doi: 10.1016/j.jsams.2011.03.009. Harwood, C. G., \& Knight, C. J. (2015). Parenting in youth sport: A position paper on parenting expertise. Psychology of Sport and Exercise, 16, 24-35. doi: 10.1016/j.psychsport.2014.03.001. 
Hern, D., Vujaklija, A., Ivanisevic, R., Knezevic, J., Marusic, M., \& Marusic, A. (2006). Students' moral reasoning, Machiavellianism, and socially desirable responding: Implications for teaching ethics and research integrity. Medical Education, 40(3), 269-277. doi: 10.1111/j.1365-2929.2006.02391.

Hurst, P., Kavussanu, M., Boardley, I., \& Ring, C. (2019). Sport supplement use predicts doping attitudes and likelihood via sport supplement beliefs. Journal of Sports Sciences, 37(15), 1734-1740. doi: 10.1080/02640414.2019.1589920.

Jalleh, G., Donovan, R. J., \& Jobling, I. (2014). Predicting attitudes towards performance enhancing substance use: A comprehensive test of the Sport Drug Control Model with elite Australian athletes. Journal of Science and Medicine in Sport, 17(6), 574-579. doi: 10.1016/j.jsams.2013.10.249.

Kavussanu, M., \& Boardley, I.D. (2009). The prosocial and antisocial behavior in sport scale. Journal of Sport \& Exercise Psychology, 31(1), 97-117.

Kavussanu, M. (2007). Morality in Sport. In S. Jowette \& D. Lavallee (Eds.), Social Psychology in Sport (pp. 265-277). Champaign, IL, US: Human Kinetics.

Kavussanu, M., \& Ntoumanis, N. (2003). Participation in sport and moral functioning: Does ego orientation mediate the relationship? Journal of Sport \& Exercise Psychology, 25(4), 501-518. doi: 10.1123/jsep.25.4.501.

Kavussanu, M., Ring, C., \& Hurst, P. (2018). The effects of moral disengagement on doping likelihood and guilt. Division of Sport and Exercise Psychology Annual Conference (pp. 3-4), December, Hilton, Belfast.

Kavussanu, M., \& Ring, C. (2017). Moral identity predicts doping likelihood via moral disengagement and anticipated guilt. Journal of Sport \& Exercise Psychology, 39(4), 293-301. doi: 10.1123/jsep.20160333

Kavussanu, M. (2019). Toward an understanding of transgressive behavior in sport: Progress and prospects. Psychology of Sport and Exercise, 42, 33-39. doi: 10.1016/j.psychsport.2019.01.009.

Lazuras, L., Barkoukis, V., Mallia, L., Lucidi, F., \& Brand, R. (2017). More than a feeling: The role of anticipated regret in predicting doping intentions in adolescent athletes. Psychology of Sport and Exercise, 30, 196-204. doi: 10.1016/j.psychsport.2017.03.003.

Lazuras, L., Barkoukis, V., \& Tsorbatzoudis, H. (2015). Toward an integrative model of doping use: An empirical study with adolescent athletes. Journal of Sport \& Exercise Psychology, 37(1), 37-50. doi: 10.1123/ jsep.2013-0232.

Lee, M. J., Whitehead, J., Ntoumanis, N., \& Hatzigeorgiadis, A. (2008). Relationships among values, achievement orientations, and attitudes in youth sport. Journal of Sport and Exercise Psychology, 30(5), 588610.

Loland, S. (2002). Fair play in sport: A moral norm system. London: Routledge.
Lucidi, F., Zelli, A., Mallia, L., Nicolais, G., Lazuras, L., \& Hagger, M. S. (2017). Moral attitudes predict cheating and gamesmanship behaviors among competitive tennis players. Frontiers in Psychology, 8(164), 571. doi: 10.3389/fpsyg.2017.00571.

Lyons, M., \& Brockman, C. (2017). The Dark Triad, emotional expressivity and appropriateness of emotional response: Fear and sadness when one should be happy? Personality and Individual Differences, 104, 466-469. doi: 10.1016/j.paid.2016.08.038

Madigan, D. J., Stoeber, J., \& Passfield, L. (2016). Perfectionism and attitudes towards doping in junior athletes. Journal of Sports Sciences, 34(8), 700-706. doi: 10.1080/02640414.2015.1068441.

Magnus, J. R., Polterovich, V. M., Danilov, D. L., \& Savvateev, A. V. (2002). Tolerance of cheating: An analysis across countries. The Journal of Economic Education, 33(2), 125-135.

Miller, B. W., Roberts, G. C., \& Ommundsen, Y. (2005). Effect of perceived motivational climate on moral functioning, team moral atmosphere perceptions, and the legitimacy of intentionally injurious acts among competitive youth football players. Psychology of Sport and Exercise, 6(4), 461-477. doi: 10.1016/j. psychsport.2004.04.003.

Nicholls, A. R., Madigan, D. J., Backhouse, S. H., \& Levy, A. R. (2017). Personality traits and performance enhancing drugs: The Dark Triad and doping attitudes among competitive athletes. Personality and Individual Differences, 112, 113-116. doi: 10.1016/j. paid.2017.02.062.

Nicholls, A. R., Madigan, D. J., Duncan, L., Hallward, L., Lazuras, L., Bingham, K., \& Fairs, L. R. (2019). Cheater, cheater, pumpkin eater: The Dark Triad, attitudes towards doping, and cheating behavior among athletes. European Journal of Sport Science (fortcoming), 1-19. doi: 10.1080/17461391.2019.1694079.

Nicholls, A. R., Perrya J. L., Levy A. R., Meir, R., Jones, L., Baghurst, T., Sanctuary, C., \& Thompson, M. A. (2015). Coach perceptions of performance enhancement in adolescence: The sport drug control model for adolescent athletes. Performance Enhancement \& Health, 3(2), 93-101. doi: 10.1016/j.peh.2015.07.001.

Nicholls, J. G. (1989). The competitive ethos and democratic education. Cambridge, MA: Harvard University Press.

Ntoumanis, N., Barkoukis, V., Gucciardi, D. F., \& Chan, D. K. C. (2017). Linking coach interpersonal style with athlete doping intentions and doping use: A prospective study. Journal of Sport \& Exercise Psychology, 39(3), 188-198. doi: 10.1123/jsep.20160243.

Ntoumanis, N., Ng, J., Barkoukis, V., \& Backhouse, S. (2014). Personal and psychosocial predictors of doping use in physical activity settings: A meta-analysis. Sports Medicine, 44(11), 1603-1624. doi: 10.1007/s40279014-0240-4. 
Palou, P., Ponseti, F. J., Cruz, J., Vidal, J., Cantallops, J., Borras, P. A., \& Gracia-Mas, A. (2013). Acceptance of gamesmanship and cheating in young competitive athletes in relation to the motivational climate generated by parents and coaches. Perceptual \& Motor Skills: Physical Development \& Measurement, 117(1), 290303. doi: 10.2466/10.30.PMS.117x14z9

Paulhus, D. L., \& Williams, K. M. (2002). The Dark Triad of personality: Narcissism, Machiavellianism and psychopathy. Journal of Research in Personality, 36(6), 556-563. doi: 10.1016/S0092-6566(02)00505-6.

Petróczi, A. (2013). The doping mindset-Part I: Implications of the functional use theory on mental representations of doping. Performance Enhancement \& Health, 2(4), 153-163. doi: 10.1016/j.peh.2014.06.001.

Ponseti, F. J., Cantallops, J., \& Muntaner-Mas, A. (2016). Fair play, cheating and gamesmanship in young basketball teams. Journal of Physical Education \& Health, 5(8), 29-33.

Potgieter, J. R. (2013). Cheating: The dark side of sport. South African Journal for Research in Sport, Physical Education and Recreation, 35(2), 153-162.

Raskin, R., \& Hall, C. S. (1979). A narcissistic personality inventory. Psychological Reports, 45(2), 590. doi: 10.2466/pr0.1979.45.2.590.

Ring, C., \& Kavussanu, M. (2018). The impact of achievement goals on cheating in sport. Psychology of Sport and Exercise, 35, 98-103. doi: 10.1016/j. psychsport.2017.11.016.

Russell, J. S. (2014). Is there a normatively distinctive concept of cheating in sport (or anywhere else)? Journal of the Philosophy of Sport, 41(3), 303-323. doi: /10.1080/00948705.2013.832266.

Sage, L. D., Kavussanu, M., \& Duda, J. J. (2006). Goal orientations and moral identity as predictors of prosocial and antisocial functioning in male association football players. Journal of Sport Sciences, 24(5), 455-466.

Sas-Nowosielski, K., \& Budzisz, A. (2017). Adaptive and maladaptive perfectionism and athletes' attitudes toward doping and anti-doping policy in sport. Baltic Journal of Health and Physical Activity, 9(2), 82-88.

Stoeber, J., Stoll, O., Pescheck, E., \& Otto, K. (2008). Perfectionism and achievement goals in athletes: Relations with approach and avoidance orientations in mastery and performance goals. Psychology of Sport and Exercise, 9(2), 102-121. doi: 10.1016/j. psychsport.2007.02.002.

Strand, B., Brotherson, S., \& Tracy, T. (2018). Gamesmanship beliefs and ethical decision making of college athletes. Physical Educator, 75(2), 302-320. doi: 10.18666/TPE-2018-V75-I2-7522.

Šukys, S. (2013). Athletes' justification of cheating in sport: Relationship with moral disengagement in sport and personal factors. Baltic Journal of Sport and Health Sciences, 3(90), 70-77.

Šukys, S., Karanauskienè, D., \& Šmigelskaite, J. (2019). Qualitative investigation of athletes' perceptions of cheating in sport. Baltic Journal of Sport and Health Sciences, 3(114), 33-41.

Šukys, S., \& Nickus, E. (2010). Coaches' attitudes towards deception in sports activities. Sporto mokslas, 1(59), 28-35.

Vorstenbosch, J. (2010). Doping and Cheating. Journal of the Philosophy of Sport, 37(2), 166-181. doi: 10.1080/00948705.2010.9714774.

Zucchetti, G., Candela, F., \& Villosio, C. (2015). Psychological and social correlates of doping attitudes among Italian athletes. International Journal of Drug Policy, 26(2). doi: 10.1016/j.drugpo.2014.07.021. 